\title{
Giombo persimmon seed (GPS) an alternative adsorbent for the removal Toluidine Blue dye from aqueous solutions
}

\author{
Marilice S. Bretanha, Guilherme L. Dotto, Julio C.P. Vaghetti, Silvio L.P. Dias, \\ Eder C. Lima \& Flavio A. Pavan
}

To cite this article: Marilice S. Bretanha, Guilherme L. Dotto, Julio C.P. Vaghetti, Silvio L.P. Dias, Eder C. Lima \& Flavio A. Pavan (2016): Giombo persimmon seed (GPS) an alternative adsorbent for the removal Toluidine Blue dye from aqueous solutions, Desalination and Water Treatment

To link to this article: http://dx.doi.org/10.1080/19443994.2016.1179223

\section{Published online: 03 May 2016.}

Submit your article to this journal ऍ

View related articles $\nearrow$

View Crossmark data $₫$ 


\title{
Giombo persimmon seed (GPS) an alternative adsorbent for the removal Toluidine Blue dye from aqueous solutions
}

\author{
Marilice S. Bretanha ${ }^{a}$, Guilherme L. Dotto ${ }^{b}$, Julio C.P. Vaghettic, Silvio L.P. Dias ${ }^{c}$, \\ Eder C. Lima ${ }^{\mathrm{c}}$, Flavio A. Pavan ${ }^{\mathrm{a}, *}$ \\ ${ }^{a}$ Research of Program of Post-graduate in Engineering-PPEng, Federal University of Pampa, UNIPAMPA, Bagé, RS, Brazil, \\ email: bretanham@gmail.com (M.S. Bretanha), Tel. +55 53 32472367; email: flavio.pavan@unipampa.edu.br (F.A. Pavan) \\ ${ }^{b}$ Chemical Engineering Department, Federal University of Santa Maria, UFSM, Santa Maria, RS, Brazil, \\ email: guilherme_dotto@yahoo.com.br \\ ${ }^{c}$ Institute of Chemistry, Federal University of Rio Grande do Sul, UFRGS, Porto Alegre, RS, Brazil, emails: juliovaghetti@gmail.com \\ (J.C.P.Vaghetti), silvio.dias@ufrgs.br (S.L.P. Dias), profederlima@gmail.com (E.C. Lima)
}

Received 12 December 2015; Accepted 11 April 2016

\begin{abstract}
Giombo persimmon seeds (GPS) (Diospyrus kaki L) were used as a novel low-cost adsorbent for the removal of Toluidine Blue dye (TB) from aqueous solution by batch contact adsorption mode at $25^{\circ} \mathrm{C}$. The GPS adsorbent was characterized by specific surface area (Brunauer-Emmett-Teller), scanning electron microscopy, infrared spectroscopy (ATR-FTIR), thermal analysis, point of zero charge, and Boehm titration techniques. The effects of initial $\mathrm{pH}$ of solution, adsorbent dosage, contact time, and initial dye concentration on TB adsorption were investigated. Kinetic data were evaluated by pseudo-first-order, pseudosecond-order, and Elovich models. The equilibrium adsorption was analyzed by Langmuir, Freundlich, and Sips isotherms models. Desorption studies were also performed. The results indicated that the Elovich model agreed very well with the kinetic data. The equilibrium data of adsorption of TB onto GPS were better fitted using Sips isotherm. The maximum adsorption capacity was $34.73 \mathrm{mg} \mathrm{g}^{-1}$. Good regeneration (93.5\%) of GPS adsorbent was obtained using $2.00 \mathrm{~mol} \mathrm{~L}^{-1} \mathrm{CH}_{3} \mathrm{COOH}$ as eluent. The GPS adsorbent can be used in the future as an alternative low-cost adsorbent for the treatment of waters contaminated with TB dye.
\end{abstract}

Keywords: Adsorption; Diospyrus kaki L. seeds; Toluidine Blue; Simulated effluent

\section{Introduction}

The deleterious effects of dyes and pigments on ecosystems and on human health are well known. Many of these organic compounds are commonly toxic and even carcinogenic representing a great threat to life [1-3]. The presence of these dyes in water can

*Corresponding author. affect the photosynthesis, reducing significantly water qualities [4]. The biggest problem to remove dyes from aqueous media is their stability, high solubility, and low degradability [5]. For these reasons, several studies have been conducted to eliminate color from wastewater using various methods. Among the existing methods for the dye removal from aqueous media, adsorption has been widely used, since it presents

1944-3994/1944-3986 ㄷ 2016 Balaban Desalination Publications. All rights reserved. 
several operational advantages [6,7]. Activated carbon is the most commonly used adsorbent [8] and has been employed with great success, especially because its capacity to adsorb a very wide range of dyes with high adsorption capacity [9]. However, activated carbon is expensive with high regeneration costs, hindering its application specially when used at large quantities [10]. Nowadays, in order to decrease the cost of wastewater treatment, a large variety of low cost adsorbents have been prepared and their adsorptive capacities investigated under different experimental conditions [11,12]. Several alternative low-cost adsorbents, including waste agricultural and forestry materials have been used with success on color removal from aqueous solution [13-16]. Nevertheless, studies involving the use of Giombo persimmon seed for the dye removal from aqueous are still very scarce.

In the present investigation, Giombo persimmon seeds (GPS) (Diospyrus kaki L) were prepared, characterized, and used for the first time as an alternative low-cost adsorbent for the removal of Toluidine Blue (TB) from aqueous solutions. TB, a phenothiazine dye, was chosen for this investigation because it is widely used in several fields such as textile industry, biotechnology, and medicine science [17]. Thus, large quantities of colored effluents containing TB dye are generated annually and these effluents must be treated.

The persimmon tree is grown mainly in the south and southeast of Brazil country [18,19]. It is a fruit with spherical shapes, slightly flattened, and can be of several colorations (yellow, dark purple light, purple dark light yellow, orange or red) and, its seeds are flattened and brown coloration. Persimmon 'Giombo' belongs to the variable group, which has clear and astringent pulp, when the parthenocarpic fruit development occurs, and no astringent and dark pulp in the presence of seeds. Persimmon production in Brazil is intended almost entirely for the consumption of fresh fruit and after the consumption of fruit, the seeds are discarded.

The goal of this work was to investigate the adsorption of TB dye from aqueous solutions on GPS under various adsorption conditions. Characterization studies of GPS adsorbent, such as, specific surface area (Brunauer-Emmett-Teller (BET)), scanning electron microscopy (SEM), thermal analysis (TA), Boehm titration, and point of zero charge $\left(\mathrm{pH}_{\mathrm{PZC}}\right)$ were performed in order to determine the interactions between TB molecules and adsorbent in the solid-liquid interface. The effects of $\mathrm{pH}$ of solution, adsorbent dosage, initial dye concentration, and contact time were investigated using batch adsorption procedure at $25.0^{\circ} \mathrm{C}$. Equilibrium isotherm and kinetic data were fitted with adequate models, using nonlinear regression analysis.

\section{Materials and methods}

\subsection{Reagents and solutions}

TB cationic dye (C.I. number 52040; Basic Blue 17; empirical formula $\mathrm{C}_{15} \mathrm{H}_{16} \mathrm{~N}_{3} \mathrm{SCl}$, molecular weight $305.8 \mathrm{~g} \mathrm{~mol}^{-1}$ ) was obtained from Sigma Chemical Co., USA, with analytical grade. The TB chemical structure is presented in Fig. 1. The salts $\mathrm{NaCl}, \mathrm{Na}_{2} \mathrm{CO}_{3}, \mathrm{CaCl}_{2}$, $\mathrm{Mg}_{2} \mathrm{SO}_{4}, \mathrm{KCl},\left(\mathrm{NH}_{4}\right)_{2} \mathrm{HPO}_{4}$, and $\mathrm{CH}_{3} \mathrm{COOH}$ were purchased from Synth Brazil. The sodium hydroxide $(\mathrm{NaOH})$, hydrochloride acid $(\mathrm{HCl})$ used were from Merck Ltda., Brazil.

The TB stock solution was prepared by dissolving accurately the weighed dye in deionized water to obtain the concentration of $1,000.0 \mathrm{mg} \mathrm{L}^{-1}$. Working solutions were obtained by diluting the dye stock solution to the required concentrations. Deionized water was used throughout for solution preparations. The initial $\mathrm{pH}$ of each solution was adjusted with $0.10 \mathrm{~mol} \mathrm{~L}^{-1} \mathrm{NaOH}$ or $\mathrm{HCl}$ solutions using a $\mathrm{pH}$-meter (Digimed, DM 20, Brazil) for the measurements.

\subsection{Adsorbent preparation}

GPS was obtained at local market. The seeds were removed manually from fresh fruit and washed with distilled water to remove dust and other impurities. Afterwards, the seeds were dried at $60.0^{\circ} \mathrm{C}$ for $24 \mathrm{~h}$ (Sterilifer, SX450A, Brazil), crushed in a mill (Quimis, Q298A21, Brazil) and sieved through a $250 \mu \mathrm{m}$ sieve. Subsequently, the seeds were washed with doubly distilled water and then oven dried at $60.0^{\circ} \mathrm{C}$ for $48 \mathrm{~h}$ (Sterilifer, SX450A, Brazil). The powdered seeds obtained were then named as GPS [20].
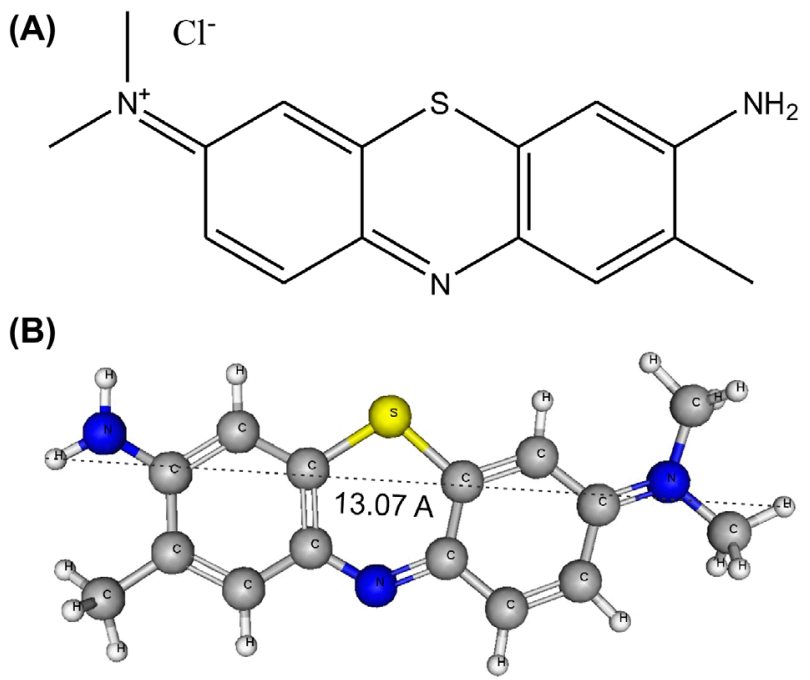

Fig. 1. TB dye: (A) chemical structure and (B) threedimensional formula. 


\subsection{Characterization of GPS adsorbent}

The specific surface area and porosity of GPS were determined by the BET and Barrett-Joyner-Halenda (BJH) methods by the $\mathrm{N}_{2}$ adsorption technique using a surface area analyzer (Quantasorb, QS-7, USA). The GPS was previously degassed at $120.0^{\circ} \mathrm{C}$ in vacuum for $12 \mathrm{~h} . \mathrm{N}_{2}$ analysis was carried out using a temperature of $-196.0^{\circ} \mathrm{C}$ [21].

The point zero charge $\left(\mathrm{pH}_{\mathrm{zpc}}\right)$ of the GPS was determined by variations of $\mathrm{pH}$ solution when in contact with the solid adsorbent using the following procedure: $50.0 \mathrm{~mL}$ of $0.10 \mathrm{~mol} \mathrm{~L}^{-1} \mathrm{NaCl}$ solution was placed in a closed $100.0 \mathrm{~mL}$ capped Erlenmeyer flask. The $\mathrm{pH}$ of each solution was adjusted to values of 2.0-10.0 using $0.1 \mathrm{~mol} \mathrm{~L}^{-1} \mathrm{HCl}$ or $\mathrm{NaOH}$. An amount of $0.200 \mathrm{~g}$ of GPS was added to the flask and the final $\mathrm{pH}\left(\mathrm{pH}_{\mathrm{f}}\right)$ was measured after $48 \mathrm{~h}$ under stirring at $25.0^{\circ} \mathrm{C}$. The $\mathrm{pH}_{\mathrm{zpc}}$ is the point where the curve $\mathrm{pH}$ final $\left(\mathrm{pH}_{\mathrm{f}}\right)$ vs. initial $\mathrm{pH}\left(\mathrm{pH}_{\mathrm{i}}\right)$ crosses the line and equals to final $\mathrm{pH}\left(\mathrm{pH}_{\mathrm{f}}\right)$ [22].

The concentrations of acid groups (carboxylic, phenol and lactonic) present onto GPS were determined by the Boehm titration method [23]. Analyses of moisture, ashes, and specific density were carried out according to the methodology of Association Official of Analytical Chemistry [24].

The investigation of surface structure and morphology of native GPS and dye-loaded GPS adsorbent was made by SEM (Jeol, JSM 5800, Japan) with working voltage of $10 \mathrm{kV}$ at magnification 2,500 times [25].

The superficial chemical groups of GPS were identified by (FTIR-ATR) spectroscopy (Shimadzu, 8300, Japan). The spectra were obtained with a resolution of $4 \mathrm{~cm}^{-1}$ with 100 cumulative scans over the range of $4,000-1,000 \mathrm{~cm}^{-1}$ [26].

Thermogravimetric (TG) curve of GPS was carried out using a thermogravimetric analyzer TGA (Q5000IR, TA instrument, USA) under experimental conditions: initial temperature $50^{\circ} \mathrm{C}$; final temperature $700.0^{\circ} \mathrm{C}$; heating rate: $10^{\circ} \mathrm{C} \mathrm{min}{ }^{-1}$; and nitrogen flow rate $25.0 \mathrm{~mL} \mathrm{~min}^{-1}$ [20].

\subsection{Batch adsorption and desorption experiments}

The effects of initial $\mathrm{pH}$ of dye solution, adsorbent dosage, contact time between the adsorbent and dye and initial dye concentration on TB adsorption by GPS were studied using batch adsorption method at $25^{\circ} \mathrm{C}$. These experiments were performed with $50.0 \mathrm{~mL}$ of TB solution (initial concentration $50.0 \mathrm{mg} \mathrm{L}^{-1}$ ), at different contact times (5.0-300.0 min), adsorbent dosage $(0.2-1.2 \mathrm{~g} / 50.0 \mathrm{~mL})$, and $\mathrm{pH}$ values (2.0-10.0). For adsorption equilibrium studies, $0.4 \mathrm{~g}$ adsorbent was placed in a series of conical flasks $(125.0 \mathrm{~mL})$ each one containing $50.0 \mathrm{~mL}$ of different initial dye concentrations $\left(1.0-1,000.0 \mathrm{mg} \mathrm{L}^{-1}\right)$ at $\mathrm{pH}$ 8.0. The conical flasks were shaken in a rotary orbital shaker at $150.0 \mathrm{rpm}$ for 180.0 min (Quimis, G225 M, Brazil). The adsorbent was separated from the liquid phase by centrifugation (Quimis, Q222T216, Brazil) and the remaining dye in the solution was then determined using a UV-vis spectrophotometer (Varian, Cary 50 Bio, USA) with $1.0 \mathrm{~cm}$ path length cell at $630.0 \mathrm{~nm}$. The experiments were carried out in replicate $(n=3)$ and blanks were performed. The amount of dye adsorbed per gram of adsorbate at equilibrium $\left(q_{\mathrm{e}}\right)$ at any time $\left(q_{t}\right)$ and the dye removal percentage $(R \%)$ was obtained by the Eqs. (1)-(3) $[27,28]$, respectively:

$q_{\mathrm{e}}=\frac{C_{0}-C_{\mathrm{e}}}{m} V$

$q_{t}=\frac{C_{0}-C_{t}}{m} V$

$R \%=\frac{C_{0}-C_{\mathrm{e}}}{C_{0}} 100$

where $C_{0}$ is the initial TB concentration $\left(\mathrm{mg} \mathrm{L}^{-1}\right), C_{\mathrm{e}}$ is the equilibrium $\mathrm{TB}$ concentration $\left(\mathrm{mg} \mathrm{L}^{-1}\right), C_{t}$ is the $\mathrm{TB}$ concentration at any time $\left(\mathrm{mg} \mathrm{L}^{-1}\right), m$ is the adsorbent amount $(\mathrm{g})$, and $V$ is the volume of dye solution (L).

Batch desorption studies were carried with goal to restore the adsorbent, using $\mathrm{CH}_{3} \mathrm{COOH}$, as the eluent. For this propose, $0.4 \mathrm{~g}$ of dye-loaded adsorbent obtained from more adequate adsorption conditions $\left(T=25^{\circ} \mathrm{C}\right.$, adsorbent dosage $=0.4 \mathrm{~g} / 50.0 \mathrm{~mL}$ and contact time $=180.0 \mathrm{~min}$ ) was mixed with $50.0 \mathrm{~mL}$ of $0.05-2.00 \mathrm{~mol} \mathrm{~L}^{-1} \mathrm{CH}_{3} \mathrm{COOH}$ solution in Erlenmeyer flasks, the mixture was agitated with help of rotator shaker at $150.0 \mathrm{rpm}$ for $180.0 \mathrm{~min}$ to reach equilibrium. Afterward, the samples were centrifuged at $5,000.0 \mathrm{rpm}$ for $15.0 \mathrm{~min}$, the dye concentration released on the desorbing solution was determined at the maximum wavelength of TB dye $(630.0 \mathrm{~nm})$.

\subsection{Kinetic and equilibrium models}

To study the kinetics of adsorption of $\mathrm{TB}$ on the GPS, three different kinetic models, namely pseudofirst-order [29], pseudo-second-order [30], and Elovich [31] were employed.

The non-linear form of the pseudo-first-order rate equation is given as: 
$q_{t}=q_{\mathrm{e}}\left[1-\exp \left(-k_{\mathrm{f}} t\right)\right]$

where $q_{\mathrm{e}}$ and $q_{t}$ are the amounts of $\mathrm{TB}$ adsorbed $\left(\mathrm{mg} \mathrm{g}^{-1}\right)$ at equilibrium and at a predetermined time $(t)$, respectively, and $k_{\mathrm{f}}\left(\mathrm{min}^{-1}\right)$ is the rate constant of this equation. The values of pseudo-first-order rate constants, $k_{\mathrm{f}}$, and $q_{\mathrm{e}}$ values are listed in Table 1 .

The non-linear form of the pseudo-second-order rate equation is expressed as:

$q_{t}=\frac{k_{\mathrm{s}} q_{\mathrm{e}}^{2} t}{1+q_{\mathrm{e}} k_{\mathrm{s}} \mathrm{t}}$

where $k_{\mathrm{s}}\left(\mathrm{g} \mathrm{mg}^{-1} \mathrm{~min}^{-1}\right)$ is the pseudo-second-order rate constant. The values of $q_{\mathrm{e}}, k_{\mathrm{s}}$ and $h$ obtained from this rate model are given in Table 1.

The Elovich model has been widely used in adsorption kinetics to describe chemical adsorption mechanism because it is based on a general secondorder reaction mechanism for heterogeneous adsorption processes.

The non-linear form of the Elovich equation is expressed as:

$q_{t}=\frac{1}{\beta}(\alpha \beta)+\frac{1}{\beta}(t)$

Table 1

Kinetic parameters for TB adsorption by GPS at more adequate conditions

\begin{tabular}{lll}
\hline & \multicolumn{2}{l}{$C_{0}\left(\mathrm{mg} \mathrm{L}^{-1}\right)$} \\
\cline { 2 - 3 } Model & 20.00 & 50.00 \\
\hline Pseudo-first-order & Parameters & \\
$k_{\mathrm{f}}\left(\mathrm{min}^{-1}\right)$ & $0.030 \pm 0.002$ & $0.248 \pm 0.01$ \\
$q_{\mathrm{e}}\left(\mathrm{mg} \mathrm{g}^{-1}\right)$ & $2.25 \pm 0.121$ & $5.20 \pm 0.050$ \\
$R^{2}$ & 0.865 & 0.690 \\
$\chi^{2}$ & $1.81 \times 10^{-1}$ & $2.83 \times 10^{-1}$ \\
& & \\
Pseudo-second-order & Parameters & \\
$k_{\mathrm{s}}\left(\mathrm{g} \mathrm{mg}^{-1} \mathrm{~min}^{-1}\right)$ & $0.019 \pm 0.002$ & $0.090 \pm 0.003$ \\
$q_{\mathrm{e}}\left(\mathrm{mg} \mathrm{g}^{-1}\right)$ & $2.46 \pm 0.230$ & $5.37 \pm 0.121$ \\
$h_{0}\left(\mathrm{mg} \mathrm{g}^{-1} \mathrm{~min}^{-1}\right)$ & 20 & 18 \\
$R^{2}$ & 0.925 & 0.911 \\
$\chi^{2}$ & $5.0 \times 10^{-2}$ & $4.1 \times 10^{-2}$ \\
Elovich model $^{2}$ & & \\
$\alpha\left(\mathrm{mg} \mathrm{g}^{-1} \mathrm{~min}^{-1}\right)$ & Parameters & \\
$\beta\left(\mathrm{g} \mathrm{mg}^{-1}\right)$ & 0.454 & 2.944 \\
$R^{2}$ & 2.428 & $14,856.521$ \\
$\chi^{2}$ & 0.959 & 0.940 \\
$q_{\mathrm{e}, \text { exp }}\left(\mathrm{mg} \mathrm{g}^{-1}\right)$ & $1.62 \times 10^{-2}$ & $1.04 \times 10^{-2}$ \\
\hline
\end{tabular}

where $\alpha\left(\mathrm{mg} \mathrm{g}^{-1} \mathrm{~min}^{-1}\right)$ is the initial adsorption rate and $\beta\left(\mathrm{g} \mathrm{mg}^{-1}\right)$ is desorption constant. The kinetic parameters are summarized in Table 1.

To study the equilibrium isotherms of TB dye onto GPS adsorbent, the Langmuir [32], Freundlich [33], and Sips [34] isotherm models were used.

The non-linear form of the Langmuir equation is given as:

$q_{\mathrm{e}}=\frac{Q_{\max } K_{\mathrm{L}} C_{\mathrm{e}}}{1+K_{\mathrm{L}} C_{\mathrm{e}}}$

where $C_{\mathrm{e}}$ is the concentration of $\mathrm{TB}$ in solution at equilibrium $\left(\mathrm{mg} \mathrm{L}^{-1}\right), q_{\mathrm{e}}$ is the adsorption capacity at equilibrium $\left(\mathrm{mg} \mathrm{g}^{-1}\right)$. The Langmuir isotherm implies a monolayer adsorption on the homogeneous surface. The Langmuir constant, $Q_{\max }\left(\mathrm{mg} \mathrm{g}^{-1}\right)$ is related to the maximum adsorption capacity $\left(\mathrm{mg} \mathrm{g}^{-1}\right)$ of the adsorbent and $K_{\mathrm{L}}$ is the Langmuir equilibrium constant $\left(\mathrm{L} \mathrm{mg}^{-1}\right)$. The maximum adsorption capacity $\left(Q_{\max }\right)$ of the GPS for TB was $54.54 \mathrm{mg} \mathrm{g}^{-1}$ (Table 2).

A non-linear form of Freundlich equation is:

$q_{\mathrm{e}}=K_{\mathrm{F}} C_{\mathrm{e}}^{1 / n_{\mathrm{F}}}$

where $K_{\mathrm{F}}\left(\mathrm{L} \mathrm{g}^{-1}\right)$ is the Freundlich constant related to the adsorption capacity and $1 / n$ measures the surface heterogeneity. The Freundlich equation is an empirical

Table 2

Isotherm parameters and error analysis, $\chi^{2}$ for TB adsorption by GPS at optimal adsorption conditions

\begin{tabular}{ll}
\hline Langmuir parameters & \\
$Q_{\max }\left(\mathrm{mg} \mathrm{g}^{-1}\right)$ & $54.54 \pm 0.201$ \\
$K_{\mathrm{L}}\left(\mathrm{L} \mathrm{mg}^{-1}\right)$ & 0.004 \\
$R^{2}$ & 0.994 \\
$\chi^{2}$ & 0.06
\end{tabular}

Freundlich parameters

$K_{\mathrm{F}}\left(\mathrm{mg} \mathrm{g}^{-1}\left(\mathrm{mg} \mathrm{L}^{-1}\right)^{-1 / n_{\mathrm{F}}}\right) \quad 0.568$

$n_{\mathrm{F}} \quad 1.392$

$\begin{array}{ll}R^{2} & 0.985\end{array}$

$\chi^{2}-0.11$

Sips parameters

$Q_{\max }\left(\mathrm{mg} \mathrm{g}^{-1}\right) \quad 34.73 \pm 1.023$

$K_{\mathrm{S}}\left(\mathrm{mg} \mathrm{L}^{-1}\right)^{-1 / n \mathrm{~s}} \quad 0.0016$

$\begin{array}{ll}N_{\mathrm{s}} & 0.719\end{array}$

$\begin{array}{ll}N_{\mathrm{s}} & 0.997 \\ R^{2} & 0.719\end{array}$

$\chi^{2} \quad 0.03$

$q_{\mathrm{e}, \exp }\left(\mathrm{mg} \mathrm{g}^{-1}\right) \quad 24.90 \pm 1.765$ 
model, which considers that the adsorption occurs on a heterogeneous surface and the active sites have different energies.

The Sips model is expressed as:

$q_{\mathrm{e}}=\frac{Q_{\mathrm{S}} K_{\mathrm{S}} C_{\mathrm{e}}^{1 / n}}{1+K_{\mathrm{S}} C_{\mathrm{e}}^{1 / n}}$

where $K_{\mathrm{S}}\left(\mathrm{L} \mathrm{mg}^{-1}\right)$ represents the equilibrium constant of the Sips equation and $Q_{\mathrm{S}}\left(\mathrm{mg} \mathrm{g}^{-1}\right)$ is the maximum adsorption capacity.

The kinetic and equilibrium parameters were determined by the fit of the models (Table 1) with the experimental data through nonlinear regression using the Quasi-Newton estimation method. Statistic 9.1 software (Statsoft, USA) was used for the calculations. The accuracy of the parameters was measured through the determination coefficient $\left(R^{2}\right)$ and Chi-square test $\left(\chi^{2}\right)$ [35].

\subsection{Applications of GPS adsorbent on simulated effluent}

In order to verify real possibility of applying the GPS adsorbent for the TB removal, a simulated effluent contend organic and inorganic species commonly present in wastewater was prepared. The effluent was prepared as previously described [36]. The simulated river effluent ( $\mathrm{pH}$ of 6.0) contains the following substances: $\mathrm{CaCl}_{2}\left(294.0 \mathrm{mg} \mathrm{L}^{-1}\right), \mathrm{NaCl}\left(216.1 \mathrm{mg} \mathrm{L}^{-1}\right)$, $\mathrm{Mg}_{2} \mathrm{SO}_{4} \quad\left(86.2 \mathrm{mg} \mathrm{L}^{-1}\right), \quad \mathrm{KCl} \quad\left(9.7 \mathrm{mg} \mathrm{L}^{-1}\right), \quad$ and $\left(\mathrm{NH}_{4}\right)_{2} \mathrm{HPO}_{4}\left(7.3 \mathrm{mg} \mathrm{L}^{-1}\right)$. The removal of TB from the simulated effluent proceeded as follows: $0.4 \mathrm{~g}$ of GPS adsorbent was placed into conic flask containing $50.0 \mathrm{~mL}$ of the simulated effluents in the presence of $20.0 \mathrm{mg} \mathrm{L}^{-1}$ of TB. The mixture was stirred at $150.0 \mathrm{rpm}$ for $180 \mathrm{~min}$. Then, the solid phase was separated by centrifugation and the TB concentration on supernatant was determined.

\section{Results and discussion}

\subsection{General characteristics of GPS}

The GPS is dark brown in coloration, have high hardness, and varied sizes. The results of analysis of specific density $\left(\mathrm{g} \mathrm{cm}^{-3}, 25.0^{\circ} \mathrm{C}\right)$, moisture (\% w.b.), and ash (\%) of GPS found were: $0.82 \pm 0.10,3.9 \pm 0.04$, and $2.31 \pm 0.20$, respectively.

The specific surface area and pore structure of GPS were obtained by $\mathrm{N}_{2}$ adsorption/desorption isotherm. The specific surface area of GPS (obtained by BET method) was $8.03 \pm 0.06 \mathrm{~m}^{2} \mathrm{~g}^{-1}$. The total pore volume was found to be $0.087 \pm 0.011 \mathrm{~cm}^{3} \mathrm{~g}^{-1}$. Commonly, materials of biological origin have low values of surface area $[37,38]$. The average pore diameter (found by BJH method) for GPS was $2.330 \mathrm{~nm}(23.30 \AA)$. Therefore, the GPS adsorbent could be considered a mixture of micropores and mesopores [39].

The oxygen functional groups (carboxylic, carbonyl and phenolic) of the surface of GPS were investigated by the Boehm titration method [23]. The aim of this study was to investigate quantitatively the existence of oxygenated groups that can assist on the TB adsorption onto GPS. Based on quantitative analysis, the concentration of oxygenated groups on GPS surface was: $1.5 \pm 0.21 \mathrm{mmol} \mathrm{g}^{-1}$ of carboxylic groups, 0.96 $\pm 0.03 \mathrm{mmol} \mathrm{g}^{-1}$ of lactonic groups, and 0.26 $\pm 0.02 \mathrm{mmol} \mathrm{g}^{-1}$ of phenolic groups.

The determination of the $\mathrm{pH}_{\mathrm{ZPC}}$ of adsorbent is very important for adsorption applications where target adsorbate has anionic or cationic state. When the solution $\mathrm{pH}$ is greater than $\mathrm{pH}_{\mathrm{ZPC}}$, its full load or external surface is negatively charged and the adsorption of cations is favored due to electrostatic attraction. On the other hand, $\mathrm{pHs}$ lower than the $\mathrm{pH}_{\mathrm{ZPC}}$, the charge on the adsorbent surface is predominantly positive, so favoring the adsorption of anions [40]. The $\mathrm{pH}_{\mathrm{ZPC}}$ of GPS found was 6.7 (figure not shown).

\subsection{SEM images}

The surface feature and morphological characteristics of native and loaded GPS adsorbent were investigated using the SEM technique and showed in Fig. 2(a) and (b), respectively. As seen from Fig. 2(a), (native GPS) it is possible clearly to observe that adsorbent has an irregular and non-compacted surface with cavities and protuberances throughout its length. The Fig. 2(b) shows the SEM image of GPS after TB adsorption. Comparing the SEM images of native (Fig. 2(a)) and loaded adsorbent (Fig. 2(a)) is possible to observe morphological changes onto the GPS surface. Fig. 2(a) shows that after TB molecules adsorption, the GPS appears to have a compacted surface, with cavities and protuberances were completely filled. The results obtained by SEM suggest the deposition of dyes molecules on adsorbent structure and thus, the occurrence of adsorption process between TB and GPS. This result is supported considering the average pore size found by the method BJH (23.30 $)$ and the longitudinal size of TB $(13.03 \AA)$ is shown in Fig. 1(B). A similar effect was reported by Han et al. [41] using lotus leaf for the removal of methylene blue and by Bhatti [42] for adsorption of Everdirect Orange-3GL and Direct Blue-67 dyes on rice husk. 

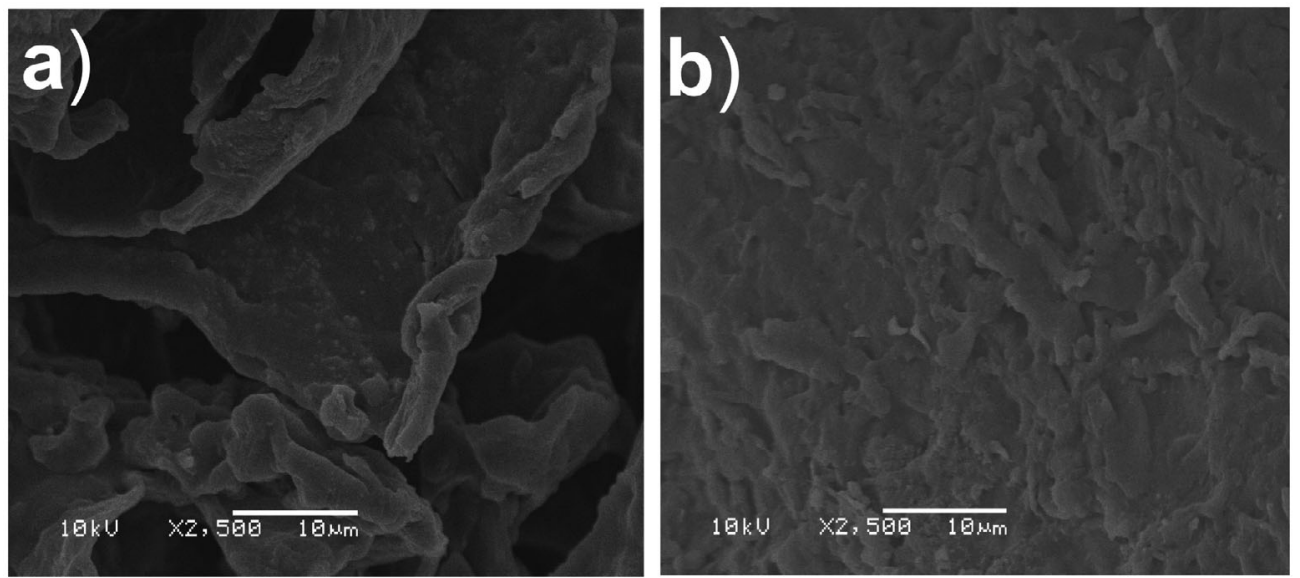

Fig. 2. SEM images of GPS (a) native and (b) loaded TB-GPS adsorbent.

\subsection{ATR-FTIR spectroscopy}

The infrared spectrums of GPS adsorbent before and after adsorption of TB are presented in Fig. 3(A) and (B), respectively. As shown in Fig. 3(A), the spectrum of unloaded GPS shows bands at $3,285 \mathrm{~cm}^{-1}$, relative to the stretch vibration of $\mathrm{OH}$ group [41]. The absorption band at $2,921 \mathrm{~cm}^{-1}$ was due to asymmetrical stretch vibration of $-\mathrm{CH}_{3}$ groups on adsorbent surface [43]. The small band at $2,855 \mathrm{~cm}^{-1}$ is assigned for symmetric stretching vibrations of $-\mathrm{CH}$ group [41]. The band at $1,745 \mathrm{~cm}^{-1}$ is characteristic of $\mathrm{C}=\mathrm{O}$ stretching [44] of ketones, aldehydes. The band at $1,602 \mathrm{~cm}^{-1}$ was attributed to stretch vibration of $\mathrm{COOH}$ from carboxylic acid with intermolecular hydrogen bond [45]. The band at $1,522 \mathrm{~cm}^{-1}$ can be assigned $\mathrm{C}=\mathrm{C}$ to aromatic rings [46]. The band at $1,433 \mathrm{~cm}^{-1}$ is due to the symmetric bending of $\mathrm{CH}_{3}$ [45]. The bands at 1,379 and 1,260 could be assigned to a bending of $\mathrm{C}-\mathrm{H}$ group [47]. The band at $1,150 \mathrm{~cm}^{-1}$ could be due to the $\mathrm{C}-\mathrm{O}$ stretching [44]. The Fig. 3(B) shows the spectrum of loaded TB-GPS adsorbent. As shown in Fig. 3(B), after TB adsorption it is possible to verify some changes on the native spectrum of GPS. When the dye is adsorbed on GPS surface, some adsorption bands were shifted: at $1,739 \mathrm{~cm}^{-1}(\mathrm{C}=\mathrm{O})$ appears at $1,745 \mathrm{~cm}^{-1}$, the band $1,602 \mathrm{~cm}^{-1}$ (C-O) was shifted to $1,612 \mathrm{~cm}^{-1}$, and the band $1,522 \mathrm{~cm}^{-1}$ (aromatic ring) appears at $1,532 \mathrm{~cm}^{-1}$. The band $1,379 \mathrm{~cm}^{-1}(\mathrm{OH})$ was shifted to $1,369 \mathrm{~cm}^{-1}$. These changes on spectral behavior after TB adsorption suggest that the functional groups such as $\mathrm{CO}$, $\mathrm{COOH}$ and $\mathrm{OH}$ are involved in interaction between TB molecules and GPS adsorbent. These results are concordance with results obtained by Saha et al. [45]. The results obtained by Boehm tritation analysis (see
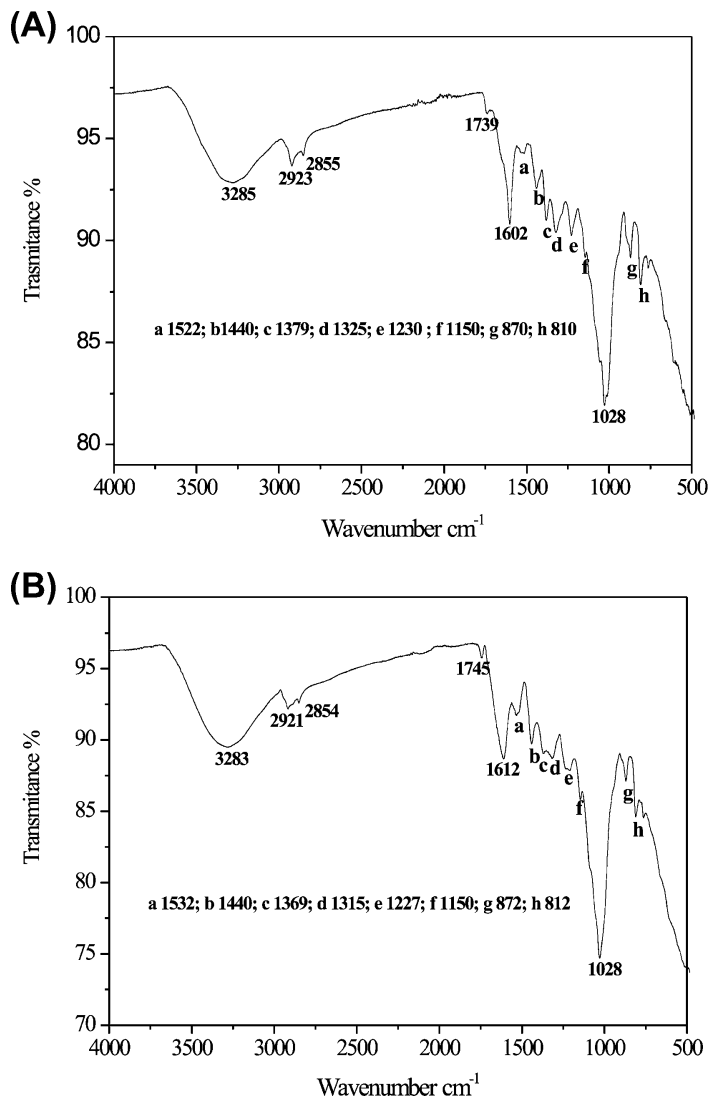

Fig. 3. ATR-FTIR spectra of GPS: (A) before TB adsorption and (B) after TB incorporation.

Section 3.1) confirm the existence of hydroxyl, carbonyl, and carboxyl groups on the surface of GPS adsorbent. 


\subsection{Interactions of TB-GPS under basic media by FTIR-} ATR technique

The results obtained on FTIR-ATR spectra of GPS before and after $\mathrm{TB}$ adsorption at $\mathrm{pH} 8.0$ (Fig. 3(A) and (B)) show the involvement of $\mathrm{OH}, \mathrm{CO}$, and $\mathrm{COOH}$ groups on $\mathrm{TB}$ adsorption. Basic conditions implied that the $\mathrm{OH}$ and $\mathrm{COOH}$ groups change to become its deprotonated form $\left(\mathrm{O}^{-}\right.$, and $\left.\mathrm{COO}^{-}\right)$. Accordingly, basic conditions, the hydroxyl and carboxyl groups are deprotonated so, this means that the GPS surface is negatively charged $\left(\mathrm{pH}_{\mathrm{zpc}}=6.7\right)$ and positively charged dyes molecules can interact strongly with $\mathrm{CO}^{-}$, and $\mathrm{COO}^{-}$as well as $\mathrm{C}=\mathrm{O}$ groups present onto adsorbent. Thus, electrostatic interaction or covalent binding between deprotonated groups on GPS surface and cationic dye (see Fig. 1) from aqueous solution could have occurred. Similar results were obtained by Saeed et al, using grapefruit peel as adsorbent for cationic dyes [48].

\subsection{TA of GPS}

The thermal behavior of GPS adsorbent was investigated by the TG technique. The TG curve of GPS adsorbent was made in $\mathrm{N}_{2}$ atmosphere and is presented in Fig. 4. In Fig. 4 are observed different weight losses regions of GPS with an increase in the temperature. The initial weight loss $\left(60-150.0^{\circ} \mathrm{C}\right)$ was attributed to the desorption of water molecules from the surface and pores of GPS [49]. The second stage the weight loss occurred between 270 and $400^{\circ} \mathrm{C}$. The second weight loss (55\%) between 270.0 and $400.0^{\circ} \mathrm{C}$ could be ascribed to the thermal degradation of hemicelluloses, lignin, and cellulose [49]. The weight loss above $400.0^{\circ} \mathrm{C}$ was attributed to carbonization of GPS.

\subsection{Effect of adsorbent mass and $\mathrm{pH}$}

The effect of GPS mass on TB adsorption was investigated. The amount of adsorbent is a very important parameter to be considered in the adsorption process. The adsorption efficiency and operating costs depend strongly on the amount of adsorbent employed. When the adsorbent is used in smaller amounts than ideal, the adsorption efficiency decreases and when used in amount above the ideal, the operating costs increasing significantly. Thus, know the ideal amount of adsorbent to obtain maximum efficiency with low cost is interesting. The dependency of adsorption efficiency of TB on GPS was investigated by varying amount GPS from 0.1 to $1.2 \mathrm{~g}$ and while keeping the parameters such as $\mathrm{pH}$, initial dye concentration $\left(50.0 \mathrm{mg} \mathrm{L}^{-1}\right)$, and contact

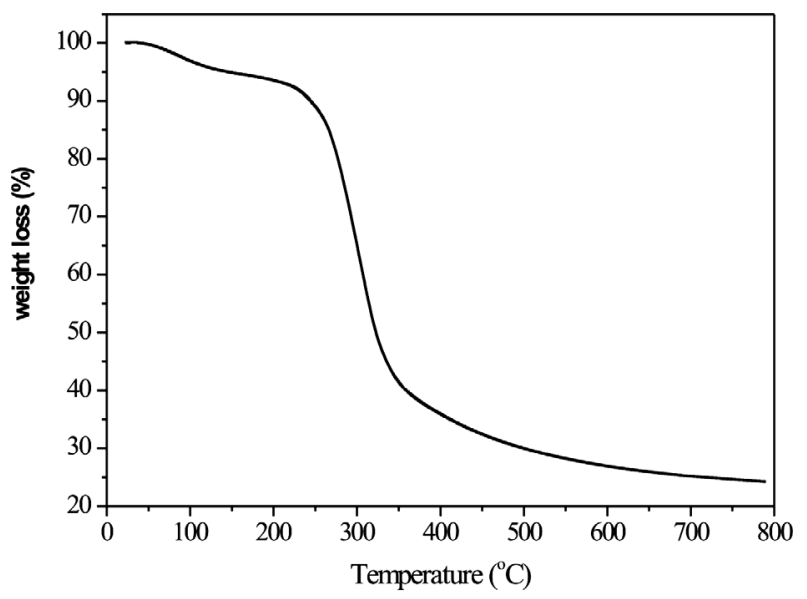

Fig. 4. TG curve of GPS adsorbent.

time (180 min). In Fig. 5(A) are presented the values of $q_{\mathrm{e}}\left(\mathrm{mg} \mathrm{g}^{-1}\right)$ and the removal of percentage $(R \%)$ of dye at different GPS dosages. Fig. 5(A) shows that when the amount of GPS was increased $0.1-0.4 \mathrm{~g}$, the $(R \%)$ increased from 58.3 to $91.7 \%$. This increase on the removal is attributed to the increase in amount surface area and vacant binding sites [50]. For adsorbent doses from 0.4 to $1.2 \mathrm{~g}$, the $(\% R)$ was constant. This result is due to the aggregation of adsorbent particles at a fixed volume solution [51,52]. As shown in Fig. 5(A), $\left(q_{\mathrm{e}}\right)$ decreased with an increase in the adsorbent dosage, an opposite behavior of $(R \%)$. With an increase in the adsorbent dosage $0.1-1.2 \mathrm{~g}$, the $q_{\mathrm{e}}$ decreased from 4.80 to 4.18 (about 15.0\%). This decrease is due to the adsorption competition among adsorbent and the split in the concentration gradient. At $0.4 \mathrm{~g}$ of GPS adsorbent, the $R \%$ and $q_{\mathrm{e}}$ were $91.7 \%$ and $4.75 \mathrm{mg} \mathrm{g}^{-1}$ respectively. Thus, adsorbent mass of $0.4 \mathrm{~g} / 50.0 \mathrm{~mL}$ was chosen to ideal for subsequently adsorption experiments.

Fig. 5(B) shows the effect of $\mathrm{pH}$ solution on adsorption capacity. It was found that when the $\mathrm{pH}$ values increased from 2.0 to 8.0 , the $q_{\mathrm{e}}$ increased from 2.47 to $5.35 \mathrm{mg} \mathrm{g}^{-1}$. For $\mathrm{pH}$ values above 8.0 , the $q_{\mathrm{e}}$ values decreased. These results show that the better $\mathrm{pH}$ value for TB adsorption on GPS is 8.0. The $\mathrm{pH}_{\mathrm{ZPC}}$ of GPS can be help to elucidate this dependency between $\mathrm{pH}$ and $q_{\mathrm{e}}$ values. Considering that $\mathrm{pH}_{\mathrm{ZPC}}$ of GPS is 6.7 and, that TB is a cationic dye, at $\mathrm{pH}$ values lower than 6.7 the surface of GPS is positively charged and electrostatic repulsion occurs, consequently, lower adsorption occurred. Similar observation has been reported by El-Sayed [53] in the removal of cationic dye by palm kernel fiber and Lakshmi [54] using rice husk ash for the removal of indigo carmine blue. 

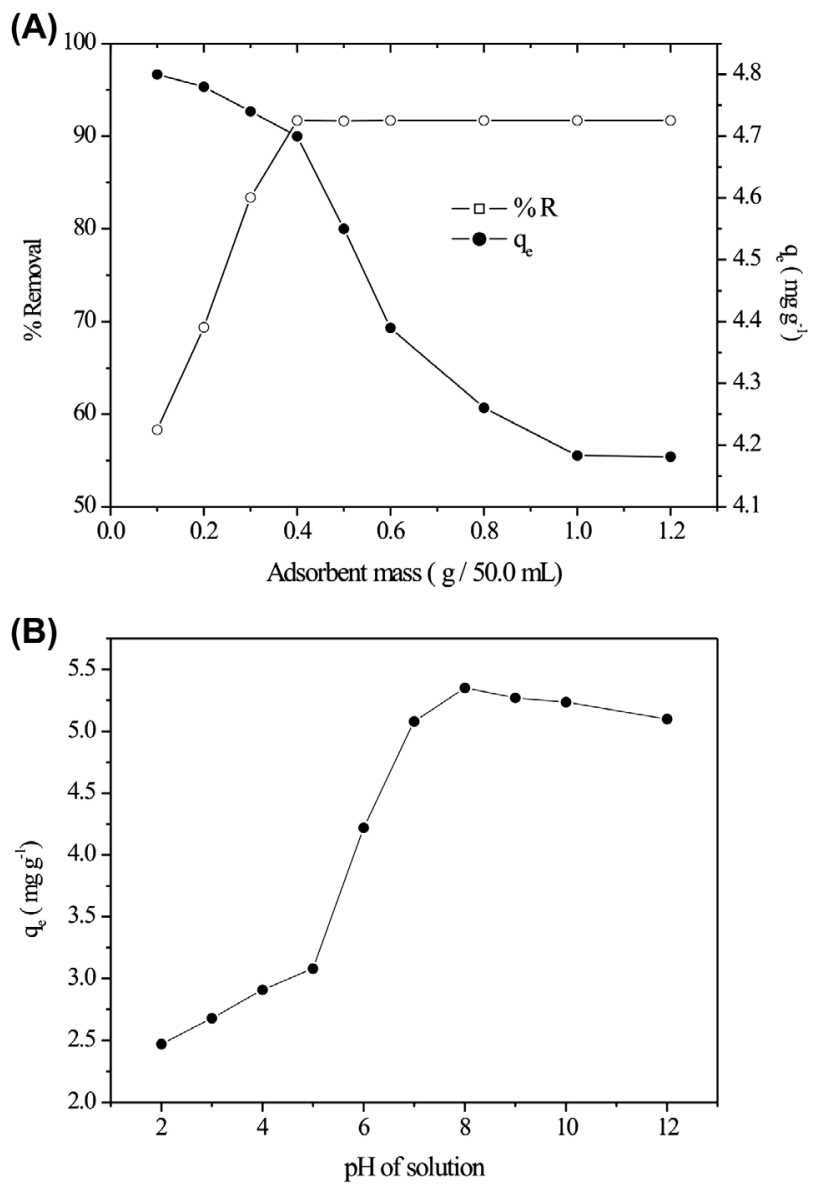

Fig. 5. Effect of (A) adsorbent mass and (B) $\mathrm{pH}$ on the adsorption of TB by GPS $\left(C_{0}=50.00 \mathrm{mg} \mathrm{L}^{-1}\right.$ and $T=25.0^{\circ} \mathrm{C}$ ).

\subsection{Effects of contact time and dye concentration}

The data of $q_{t}$ vs. $t$ for two initial dye concentrations (20.0 and $50.0 \mathrm{mg} \mathrm{L}^{-1}$ ) are shown in Fig. 6(A). Fig. 6(A) shows the dependency of adsorption capacity with contact time. The amount of TB adsorbed on GPS increased with time and later remained constant. At the first $120.0 \mathrm{~min}$, the kinetic was faster and after the adsorption rate decreased and the equilibrium was reached in $180.0 \mathrm{~min}$. This behavior can be explained considering that at initial adsorption stages there is large surface area and an abundant availability of active sites on GPS for to bind the dye molecules from solution facilitating the adsorption rate $[45,55]$. Above $180.0 \mathrm{~min}$, the kinetic adsorption was slower and the amount of adsorbed TB did not significantly changed with time. This behavior can be explained considering that, with an increase in the time, a gradual saturation of active sites on GPS surface responsible for to bind TB molecules occurs, consequently, the adsorption remains constant. Based on these results, the time chosen for TB adsorption on GPS was $180.0 \mathrm{~min}$. Fig. 6(B) shows that an increase from 20.0 to $50.0 \mathrm{mg} \mathrm{L}^{-1}$ in $\mathrm{TB}$ concentration increased the adsorption capacity from 2.34 to $5.44 \mathrm{mg} \mathrm{g}^{-1}$. This result could be attributed to the driving force that overcomes the mass transfer resistance [56].

\subsection{Kinetic studies}

The kinetic study was performed by the fit of pseudo-first-order, pseudo-second-order, and Elovich model with the experimental data. The Fig. 6(B) and (C) shows the fit of kinetic models for TB adsorption on GPS at initial dye concentrations of 20.0 and $50.0 \mathrm{mg} \mathrm{L}^{-1}$, respectively. The high values of $R^{2}$ and the low values of $\chi^{2}$ (Table 1) show that the Elovich model was the more adequate to represent the adsorption kinetics of TB onto GPS. This result indicates that exist heterogeneous active sites for TB adsorption on GPS adsorbent [57].

\subsection{Equilibrium study}

The equilibrium study was performed by the fit of Langmuir, Freundlich, and Sips models with the experimental data. The equilibrium experimental curve was obtained in the following conditions: $25.0^{\circ} \mathrm{C}, \mathrm{pH}$ of 8.0 , contact time $180.0 \mathrm{~min}$, and adsorbent dosage $0.4 \mathrm{~g} / 50.0 \mathrm{~mL}$. The initial TB concentration ranged from 1.0 to $500.0 \mathrm{mg} \mathrm{L}^{-1}$. The Sips isotherm model is characterized by the heterogeneity factor, $n$, and specifically when $n=1$, the Sips isotherm equation reduces to the Langmuir equation and it implies a homogeneous adsorption process. The maximum adsorption capacity $\left(q_{\mathrm{e}}\right)$ of the GPS obtained from the Sips isotherm was $34.73 \mathrm{mg} \mathrm{g}^{-1}$ (Table 2). The isotherm parameters, $R^{2}$, and $\chi^{2}$ are presented in Table 2 and the experimental fitted curve is presented in Fig. 7. The Fig. 7 shows that both Langmuir and Sips isotherm models adequately describe the adsorption of MB. The Sips isotherm model presents highest values of $R^{2}$ and the lowest values of $\chi^{2}$ (Table 2) when compared with the Langmuir isotherm model. The experimental data obtained did not agree with the Freundlich isotherm model. These results indicated that Sips model is more adequate to represent the adsorption equilibrium of TB onto GPS.

The maximum adsorption capacity from the Sips model $\left(Q_{\mathrm{S}}\right)$ was $34.73 \mathrm{mg} \mathrm{g}^{-1}$. This value was compared with other adsorbents used to remove TB from aqueous solutions (Table 3). The comparison shows 

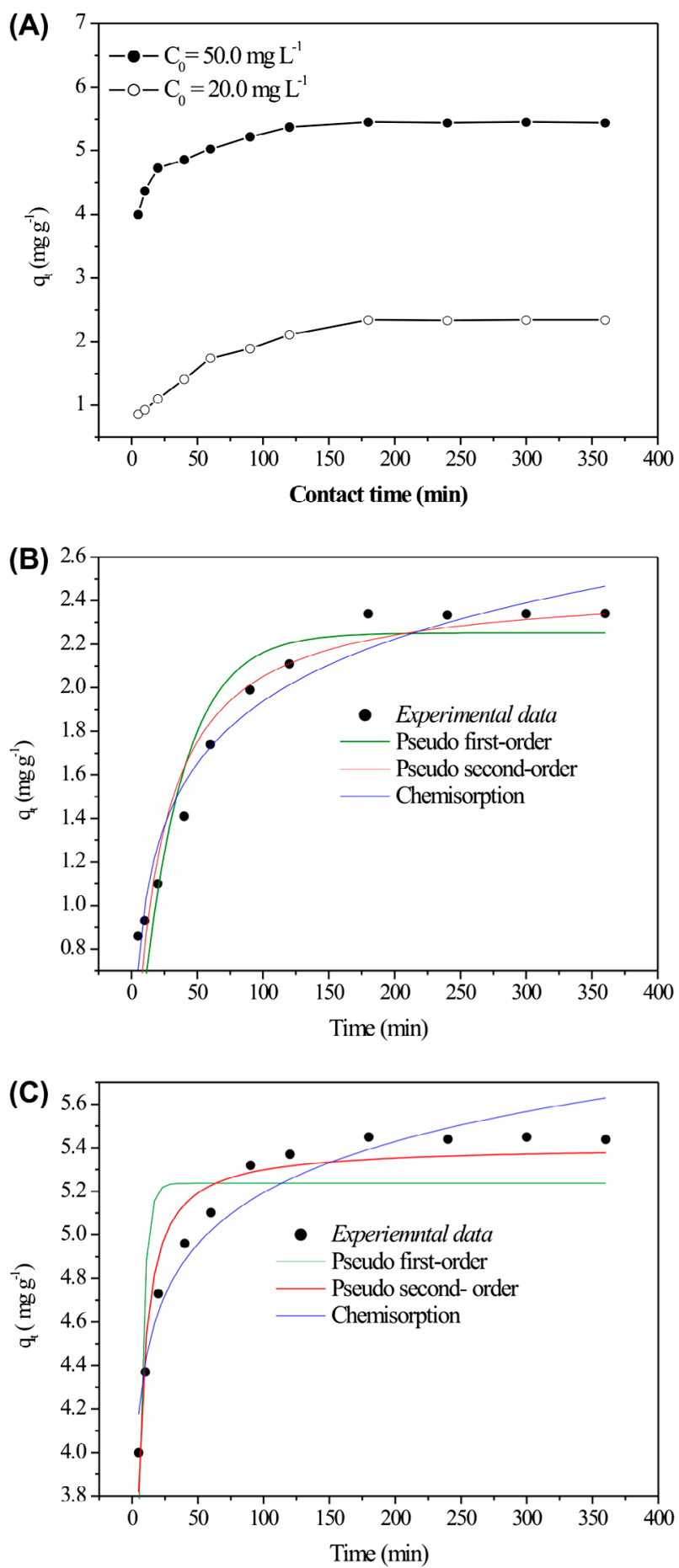

Fig. 6. Effect of contact time: (A) Kinetic curves for the adsorption of TB on GPS; (B) $C_{0}=20.0 \mathrm{mg} \mathrm{L}^{-1}$; (C) $C_{0}=50.0 \mathrm{mg} \mathrm{L}^{-1} . \quad(T=25.0 \mathrm{C}, \quad \mathrm{pH} \quad 8.0$, and adsorbent mass $=0.4 \mathrm{~g}$ ).

that GPS is a competitive low-cost adsorbent that in the future can be used for the removal of TB dye from wastewater.

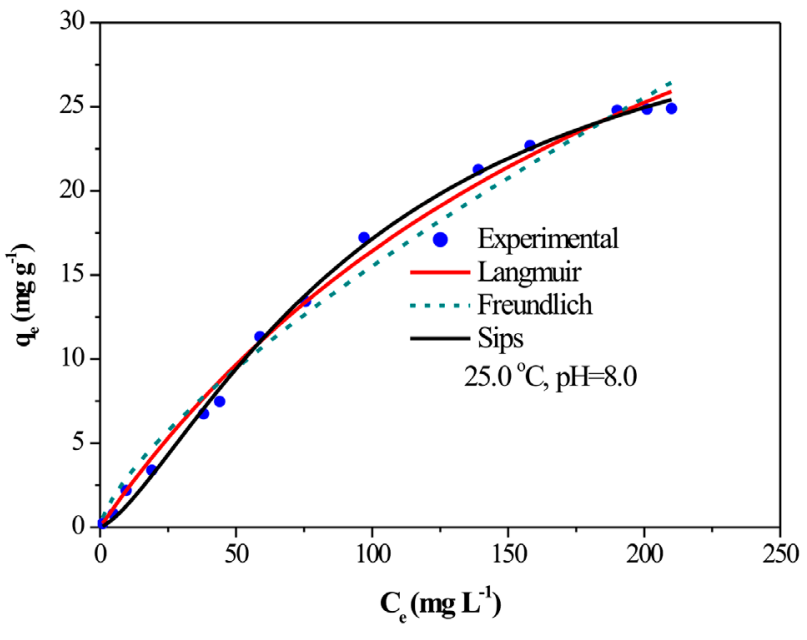

Fig. 7. Equilibrium isotherm for the adsorption of $\mathrm{TB}$ by GPS $\left(T=25.0^{\circ} \mathrm{C}\right.$, adsorbent mass $=0.4 \mathrm{~g} / 50.0 \mathrm{~mL}, \mathrm{pH} 8.0$, contact time $=180.0 \mathrm{~min}$ ).

\subsection{Batch desorption experiments}

Desorption studies were conducted to investigate the possibility of recovery of adsorbent. The results of TB desorption onto GPS adsorbent as a function of eluent $\left(\mathrm{CH}_{3} \mathrm{COOH}\right)$ concentration $\left(0.1-2.0 \mathrm{~mol} \mathrm{~L}^{-1}\right)$ are shown in Fig. 8. Examining the Fig. 8, it is possible to verify that the desorption percentage increased with increasing concentrations of eluent. The more adequate desorption condition was obtained with $2.0 \mathrm{~mol} \mathrm{~L}^{-1}$ of $\mathrm{CH}_{3} \mathrm{COOH}$, where $93.6 \%$ of $\mathrm{TB}$ was desorbed. The explanation for these results is that with an increase in the concentration of $\mathrm{CH}_{3} \mathrm{COOH}$, an increase in the hydrogen ions concentration on solution occurs. This increase in hydrogen ions solution lead to increase in the exchange of hydrogen ions presents in solution by dye molecules adsorbed onto adsorbent and consequently the desorption rate increase.

Considering that the desorption of $\mathrm{TB}$ on GPS occurred in acid media and that adsorption in basic media is very likely that TB adsorption onto GPS is governed by electrostatic interactions [63].

\subsection{Application of GPS for the TB removal from simulated effluent}

In order to study the applicability of GPS for the TB removal in real conditions, simulated effluent contains various compounds such as inorganic salts and organic molecules (see Section 2.5) commonly present in industry and environmental waters were prepared. Several studies have demonstrated that the presence 
Table 3

Comparison of adsorption capacities $\left(q_{\mathrm{e}}\right)$ of various adsorbents used for the TB removal

\begin{tabular}{lll}
\hline Adsorbent & Adsorption capacity $q_{\mathrm{e}}\left(\mathrm{mg} \mathrm{g}^{-1}\right)$ & Refs. \\
\hline Water-insoluble starch Sulfate & 26.56 & {$[58]$} \\
Pulp fiber & 25.00 & {$[59]$} \\
Fly ash & 6.00 & {$[60]$} \\
Gypsum & 26.00 & {$[61]$} \\
Almond shell & 72.99 & {$[62]$} \\
GPS & 34.73 & Present study \\
\hline
\end{tabular}

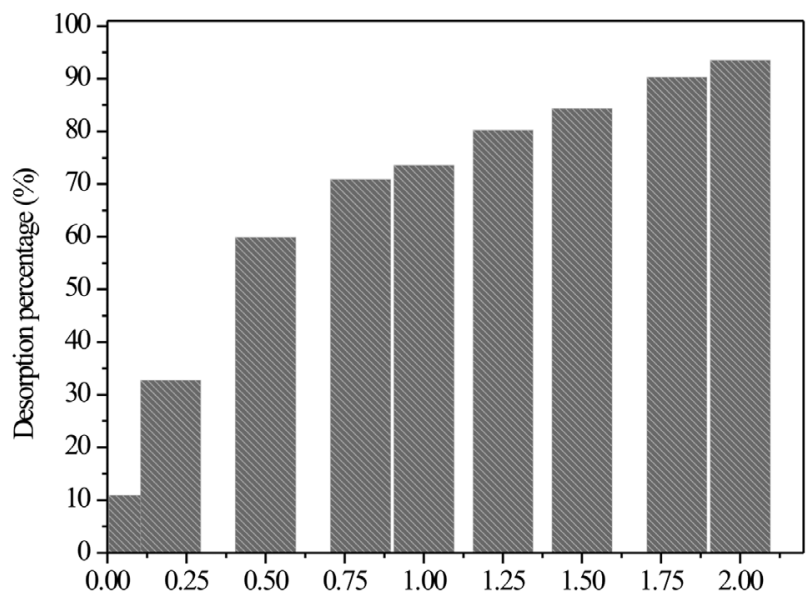

Eluent concentration $\left(\mathrm{mol} \mathrm{L}^{-1}\right)$

Fig. 8. Desorption data.

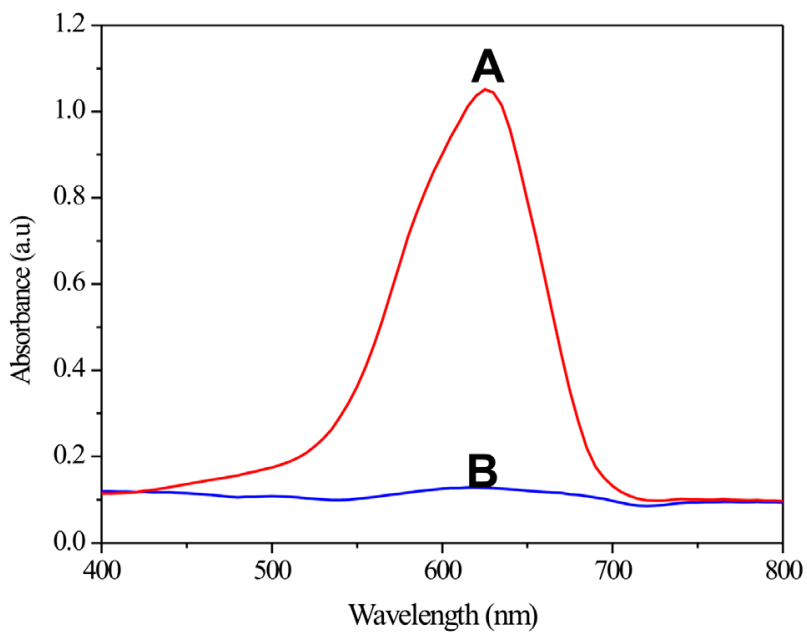

Fig. 9. Visible spectra of TB simulated effluent (A) before and (B) after treatment with GPS adsorbent. Adsorption conditions: $20.0 \mathrm{mg} \mathrm{L}^{-1} \mathrm{~TB}, 0.4 \mathrm{mg}$ GPS and $50.0 \mathrm{~mL}$ of effluent. The $\mathrm{pH}$ value of effluent is 6.0. of inorganic salts and organic molecules can affect significantly the dye molecules adsorption, limiting the potential applications of adsorbent. Fig. 9 shows the visible spectra (from 500.0 to $750.0 \mathrm{~nm}$ ) of untreated and treated simulated effluent. The intensity of band at $630.0 \mathrm{~nm}$ was used for to verify the dye percentage removal. Fig. 9 shows that after the treatment with GPS adsorbent, the bands of dye practically disappeared, indicating good efficiency of adsorbent for treating effluents. The removal efficiency found was $93.5 \pm 0.9 \%$ for $20.0 \mathrm{mg} \mathrm{L}^{-1}$ of dye. Considering the amounts of inorganic salts and organic molecules presents in the simulated effluents prepared, which are potentially able to inhibit the TB adsorption. These results obtained are quite satisfactory indicating that GPS is a promising adsorbent for the TB removal from wastewater.

\section{Conclusions}

In this work, Giombo persimmon seed (GPS) was prepared, characterized and tested as an alternative low-cost adsorbent for the removal of TB from aqueous solutions using batch procedure at room temperature. The effects of initial $\mathrm{pH}$ of solution, adsorbent dosage, contact time, and initial dye concentration were evaluated. Kinetic and equilibrium studies were performed. The potential of GPS to treat simulated effluents was verified. The results obtained by ATRFTIR indicate that carboxyl and hydroxyl groups are responsible to uptake TB molecules. The more adequate $\mathrm{pH}$ for the adsorption of TB was 8.0. The equilibrium was attained in $180.0 \mathrm{~min}$ of contact time using $0.4 \mathrm{~g} / 50.0 \mathrm{~mL}$ of adsorbent. The adsorption kinetics of TB onto GPS can be well described by the Elovich model. The Sips isotherm model is more appropriate to explain the adsorption of TB on GPS. Based on Sips isotherm model, the maximum adsorption capacity was $37.40 \mathrm{mg} \mathrm{g}^{-1}$. Desorption studies showed that GPS adsorbent can be regenerated (93.5 $\pm 0.9 \%$ ) using $2.0 \mathrm{M} \mathrm{CH}_{3} \mathrm{COOH}$ solution as an eluent. 
Based in these results, it can be concluded that Giombo persimmon seed (GPS) can be used as an alternative low-cost adsorbent for the removal of TB from aqueous media.

\section{Acknowledgments}

The authors are grateful to the CNPq, FAPERGS, and CAPES for financial support and fellowships. We are also grateful to Center of Electron Microscopy (CME-UFRGS) for the use of the SEM microscope.

\section{References}

[1] G. Bayramoglu, G. Celik, M.Y. Arica, Biosorption of Reactive Blue 4 dye by native and treated fungus Phanerocheate chrysosporium: Batch and continuous flow system studies, J. Hazard. Mater. 137 (2006) 1597-1689.

[2] Y.M. Kolekar, S.P. Pawar, K.R. Gawai, P.D. Lokhande, Y.S. Shouche, K.M. Kodam, Decolorization and degradation of Disperse Blue 79 and Acid Orange 10, by Bacillus fusiformis KMK5 isolated from the textile dye contaminated soil, Bioresour. Technol. 99 (2008) 8999-9003.

[3] M.K. Purkait, A. Maiti, S. DasGupta, S. De, Removal of congo red using activated carbon and its regeneration, J. Hazard. Mater. 145 (2007) 287-295.

[4] T. Robinson, B. Chandran, P. Nigam, Removal of dyes from a synthetic textile dye effluent by biosorption on apple pomace and wheat straw, Water Res. 36 (2002) 2824-2830.

[5] S. Wang, H.T. Li, Kinetic modelling and mechanism of dye adsorption on unburned carbon, Dyes Pigm. 72 (2007) 308-314.

[6] V.K. Gupta, I.A. Suhas, Application of low-cost adsorbents for dye removal-A review, J. Environ. Manage. 90 (2009) 2313-2342.

[7] T. Calvete, E.C. Lima, N.F. Cardoso, S.L.P. Dias, F.A. Pavan, Application of carbon adsorbents prepared from the Brazilian pine-fruit-shell for the removal of Procion Red MX 3B from aqueous solution-Kinetic, equilibrium, and thermodynamic studies, Chem. Eng. J. 155 (2009) 627-636.

[8] D. Kavitha, C. Namasivayam, Capacity of activated carbon in the removal of acid brilliant blue: Determination of equilibrium and kinetic model parameters, Chem. Eng. J. 139 (2008) 453-461.

[9] I.A.W. Tan, B.H. Hameed, A.L. Ahmad, Equilibrium and kinetic studies on basic dye adsorption by oil palm fibre activated carbon, Chem. Eng. J. 127 (2007) 111-119.

[10] M.J. Iqbal, M.N. Ashiq, Adsorption of dyes from aqueous solutions on activated charcoal, J. Hazard. Mater. 139 (2007) 57-66.

[11] A. Bhatnagar, M. Sillanpää, Utilization of agro-industrial and municipal waste materials as potential adsorbents for water treatment: A review, Chem. Eng. J. 157 (2010) 277-296.

[12] P. Sharma, H. Kaur, M. Sharma, V. Sahore, A review on applicability of naturally available adsorbents for the removal of hazardous dyes from aqueous waste, Environ. Monit. Assess. 183 (2011) 151-195.

[13] S. Patel, Potential of fruit and vegetable wastes as novel biosorbents: Summarizing the recent studies, Rev. Environ. Sci. Biotechnol. 11 (2012) 365-380.

[14] M. Ramakrishnan, S. Nagarajan, Utilization of waste biomass for the removal of basic dye from water, World Appl. Sci. J. 5 (2009) 114-121.

[15] F.A. Pavan, E.C. Lima, S.L.P. Dias, A.C. Mazzocato, Methylene blue biosorption from aqueous solutions by yellow passion fruit waste, J. Hazard. Mater. 150 (2008) 703-712.

[16] B.H. Hameed, M.I. El-Khaiary, Sorption kinetics and isotherm studies of a cationic dye using agricultural waste: Broad bean peels, J. Hazard. Mater. 154 (2008) 639-648.

[17] G. Sridharan, A.A. Shankar, Toluidine blue: A review of its chemistry and clinical utility, J. Oral Maxillofacial Pathol. 16 (2012) 251-255.

[18] M.R. Moraes, R.L Vieites, É.R. Daiuto, N.F.M. Picanço, Firmness of Giombo persimmon submitted to the postharvest application of calcium chloride, Rev. Bras. Fruticultura 33 (2011) 321-327.

[19] A. Brackmann, A.A. Saquet, Effect of temperature and controlled atmosphere conditions on the persimmon conservation (Diospyrus kaki L.) rural science, Ciênc. Rural 25 (1995) 375-378.

[20] F.A. Pavan, E.S. Camacho, E.C. Lima, G.L. Dotto, V.T.A. Branco, S.L.P. Dias, Formosa papaya seed powder (FPSP): Preparation, characterization and application as an alternative adsorbent for the removal of crystal violet from aqueous phase, J. Environ. Chem. Eng. 2 (2014) 230-238.

[21] S. Brunauer, P.H. Emmett, E. Teller, Adsorption of gases in multimolecular layers, J. Am. Chem. Soc. 60 (1938) 309-319.

[22] M. Khormaei, B. Nasernejad, M. Edrisi, T. Eslamzadeh, Copper biosorption from aqueous solutions by sour orange residue, J. Hazard. Mater. 149 (2007) 269-274.

[23] H.P. Boehm, Some aspects of the surface chemistry of carbon blacks and other carbons, Carbon 32 (1994) 759-769.

[24] Association of Official Analytical Chemistry, Official Methods of Analysis, tenth ed., Association of Official Agricultural Chemists, Washington, DC, 1965.

[25] J.I. Goldstein, D.E. Newbury, P. Echlin, D.C. Joy, A.D. Romig Jr., C.E. Lyman, C. Fiori, E. Lifshin, Scanning Electron Microscopy and X-Ray Microanalysis, Plenum Press, New York, NY, 1992.

[26] R.M. Silverstein, F.X. Webster, D.J. Kiemle, Spectrometric Identification of Organic Compounds, Wiley, New York, NY, 2007.

[27] F.A. Pavan, A.C. Mazzocato, Y. Gushikem, Removal of methylene blue dye from aqueous solutions by adsorption using yellow passion fruit peel as adsorbent, Bioresour. Technol. 99 (2008) 3162-3165.

[28] F. Deniz, S. Karaman, Removal of an azo-metal complex textile dye from colored aqueous solutions using an agro-residue, Microchem. J. 99 (2011) 296-302.

[29] S. Lagergren, About the theory of so-called adsorption of soluble substance, Kungliga Suensk Vetenskapsakademiens Handlingar 241 (1898) 1-39. 
[30] G. McKay, Y.S. Ho, Pseudo-second-order model for sorption processes, Process. Biochem. 34 (1999) 451-465.

[31] H.A. Harouna-Oumarou, H. Fauduet, C. Porte, Y.S. Ho, Comparison of kinetic models for the aqueous solid-liquid extraction of tilia sapwood in a continuous stirred tank reactor, Chem. Eng. Commun. 194 (2007) 537-552.

[32] I. Langmuir, The adsorption of gases on plane surfaces of glass, mica and platinum, J. Am. Chem. Soc. 40 (1918) 1361-1403.

[33] H.M.F. Freundlich, Uber die adsorption on Loesungen, Z. Phys. Chem. A57 (1906) 385-471.

[34] R. Sips, On the Structure of a catalyst surface, J. Chem. Phys. 16 (1948) 490-495.

[35] M.I. El-Khaiary, G.F. Malash, Common data analysis errors in batch adsorption studies, Hydrometallurgy 105 (2011) 314-320.

[36] L.D. Prola, E. Acayanka, E.C. Lima, C. Bestetti, W.O. Santos, F.A. Pavan, S.L. Dias, C.R. Tarley, Application of aqai stalks as biosorbent for the removal of Evans Blue and Vilmafix Red RR-2B dyes from aqueous solutions, Desalin. Water Treat. 51 (2013) 4582-4592.

[37] S. Jain, R.V. Jayaram, Removal of basic dyes from aqueous solution by low-cost adsorbent: Wood apple shell (Feronia acidissima), Desalination 250 (2010) 921-927.

[38] X. Han, W. Wang, X. Ma, Adsorption characteristics of methylene blue onto low cost biomass material lotus leaf, Chem. Eng. J. 171 (2011) 1-8.

[39] A. Vinu, D.P. Sawant, K. Ariga, M. Hartmann, S.B. Halligudi, Benzylation of benzene and other aromatics by benzyl chloride over mesoporous AlSBA-15 catalysts, Microporous Mesoporous Mater. 80 (2005) 195-203.

[40] S. Jain, R.V. Jayaram, Removal of basic dyes from aqueous solution by low-cost adsorbent: Wood apple shell (Feronia acidissima), Desalination 250 (2010) 921.

[41] X. Han, W. Wang, X. Ma, Adsorption characteristics of methylene blue onto low cost biomass material lotus leaf, Chem. Eng. J. 171 (2011) 1-8.

[42] Y. Safa, H.N. Bhatti, Adsorptive removal of direct textile dyes by low cost agricultural waste: Application of factorial design analysis, Chem. Eng. J. 167 (2011) 35-41.

[43] R. Gnanasambandam, A. Protor, Determination of pectin degree of esterification by diffuse reflectance Fourier transform infrared spectroscopy, Food Chem. 68 (2000) 327-332.

[44] N.V. Farinella, G.D. Matos, M.A.Z. Arruda, Grape bagasse as a potential biosorbent of metals in effluent treatments, Bioresour. Technol. 98 (2007) 1940-1946.

[45] P.D. Saha, S. Chakraborty, S. Chowdhury, Batch and continuous (fixed-bed column) biosorption of crystal violet by Artocarpus heterophyllus (jackfruit) leaf powder, Colloids Surf. B: Biointerfaces 92 (2012) 262-270.

[46] S.S. Vieira, Z.M. Magriotis, N.A.V. Santos, M. das Gracas Cardoso, A.A. Saczk, Macauba palm (Acrocomia aculeata) cake from biodiesel processing: An efficient and low cost substrate for the adsorption of dyes, Chem. Eng. J. 183 (2012) 152-161.

[47] M.B. Silveira, F.A. Pavan, N.F. Gelos, E.C. Lima, S.L.P. Dias, Punica granatum shell preparation, characteriza- tion, and use for crystal violet removal from aqueous solution, CLEAN-Soil Air Water 42 (2014) 939-946.

[48] A. Saeed, M. Sharif, M. Iqbal, Application potential of grapefruit peel as dye sorbent: Kinetics, equilibrium and mechanism of crystal violet adsorption, J. Hazard. Mater. 179 (2010) 564-572.

[49] V. Sricharoenchaikul, D. Atong, Thermal decomposition study on Jatropha curcas L. waste using TGA and fixed bed reactor, J. Anal. Appl. Pyrolysis 85 (2009) $155-162$.

[50] F. Deniz, S. Karaman, Removal of Basic Red 46 dye from aqueous solution by pine tree leaves, Chem. Eng. J. 170 (2011) 67-74.

[51] N.A. Oladoja, C.O. Aboluwoye, A.O. Akinkugbe, Evaluation of loofah as a sorbent in the decolorization of basic dye contaminated aqueous system, Ind. Eng. Chem. Res. 48 (2009) 2786-2794.

[52] Z. Yao, L. Wang, J. Qi, Biosorption of methylene blue from aqueous solution using a bioenergy forest waste: Xanthoceras sorbifolia seed coat, CLEAN-Soil Air Water 37 (2009) 642-648.

[53] G.O. El-Sayed, Removal of methylene blue and crystal violet from aqueous solutions by palm kernel fiber, Desalination 272 (2011) 225-232.

[54] U.R. Lakshmi, V.C. Srivastava, I. Deo Mall, D.H. Lataye, Rice husk ash as an effective adsorbent: Evaluation of adsorptive characteristics for Indigo Carmine dye, J. Environ. Manage. 90 (2009) 710-720.

[55] M. Iqbal, A. Saeed, Biosorption of reactive dye by loofa sponge-immobilized fungal biomass of Phanerochaete chrysosporium, Process Biochem. 42 (2007) 1160-1164.

[56] G.L. Dotto, L.A.A. Pinto, Analysis of mass transfer kinetics in the biosorption of synthetic dyes onto Spirulina platensis nanoparticles, Biochem. Eng. J. 68 (2012) 85-90.

[57] N. Thinakaran, P. Panneerselvam, P. Baskaralingam, D. Elango, S. Sivanesan, Equilibrium and kinetic studies on the removal of Acid Red 114 from aqueous solutions using activated carbons prepared from seed shells, J. Hazard. Mater. 158 (2008) 142-150.

[58] L. Guo, G. Li, J. Liu, S. Ma, J. Zhang, Kinetic and equilibrium studies on adsorptive removal of toluidine blue by water-insoluble starch sulfate, J. Chem. Eng. Data 56 (2011) 1875-1881.

[59] T.G.M. van de Ven, K. Saint-Cyr, M. Allix, Adsorption of toluidine blue on pulp fibers, Colloids Surf. A: Physicochem. Eng. Aspects 294 (2007) 1-7.

[60] R.Y. Talman, G. Atun, Effects of cationic and anionic surfactants on the adsorption of toluidine blue onto fly ash, Colloids Surf. A: Physicochem. Eng. Aspects 281 (2006) 15-22.

[61] M.A. Rauf, S.M. Qadri, S. Ashraf, K.M. Al-Mansoori, Adsorption studies of Toluidine Blue from aqueous solutions onto gypsum, Chem. Eng. J. 150 (2009) 9095.

[62] C. Duran, D. Ozdes, A. Gundogdu, H.B. Senturk, Kinetics and isotherm analysis of basic dyes adsorption onto almond shell (Prunus dulcis) as a low cost adsorbent, J. Chem. Eng. Data 56 (2011) 2136-2147.

[63] H. Patel, R.T. Vashi, Adsorption of crystal violet dye onto tamarind seed powder, E-J. Chem. 7 (2010) 975-984. 